\title{
BMJ Open Measuring perceived adequacy of staffing to incorporate nurses' judgement into hospital capacity management: a scoping review
}

\author{
Carmen J E M van der Mark (D) , ,,2 Hester Vermeulen,, ${ }^{2,3}$ Paul H J Hendriks, ${ }^{4}$ \\ Catharina $\mathrm{J}$ van Oostveen ${ }^{5,6}$
}

To cite: van der Mark CJEM, Vermeulen $\mathrm{H}$, Hendriks PHJ, et al. Measuring perceived adequacy of staffing to incorporate nurses' judgement into hospital capacity management: a scoping review. BMJ Open 2021;11:e045245. doi:10.1136/ bmjopen-2020-045245

- Prepublication history and additional supplemental material for this paper are available online. To view these files, please visit the journal online (http://dx.doi.org/10.1136/ bmjopen-2020-045245).

Received 27 September 2020 Revised 05 March 2021 Accepted 08 March 2021
Check for updates

(C) Author(s) (or their employer(s)) 2021. Re-use permitted under CC BY-NC. No commercial re-use. See rights and permissions. Published by BMJ.

For numbered affiliations see end of article.

Correspondence to

Ms Carmen J E M van der Mark; cvandermark@rijnstate.nl

\section{ABSTRACT}

Background Matching demand and supply in nursing work continues to generate debate. Current approaches focus on objective measures, such as nurses per occupied bed or patient classification. However, staff numbers do not tell the whole staffing story. The subjective measure of nurses' perceived adequacy of staffing (PAS) has the potential to enhance nurse staffing methods in a way that goes beyond traditional workload measurement or workforce planning methods.

Objectives To detect outcomes associated with nurses' PAS and the factors that influence PAS and to review the psychometric properties of instruments used to measure PAS in a hospital setting.

Design and methods A scoping review was performed to identify outcomes associated with PAS, factors influencing PAS and instruments measuring PAS. A search of PubMed, Cumulative Index to Nursing and Allied Health Literature (CINAHL), Business Source Complete and Embase databases identified 2609 potentially relevant articles. Data were independently extracted, analysed and synthesised. The quality of studies describing influencing factors or outcomes of PAS and psychometric properties of instruments measuring PAS were assessed following the National Institute for Health and Care Excellence quality appraisal checklist and the COnsensus-based Standards for the selection of health Measurement INstruments guidelines.

Results Sixty-three studies were included, describing 60 outcomes of PAS, 79 factors influencing PAS and 21 instruments measuring PAS. In general, positive PAS was related to positive outcomes for the patient, nurse and organisation, supporting the relevance of PAS as a staffing measure. We identified a variety of factors that influence PAS, including demand for care, nurse supply and organisation of care delivery. Associations between these factors and PAS were inconsistent. The quality of studies investigating the development and evaluation of instruments measuring PAS was moderate.

Conclusions Measuring the PAS may enhance nurse staffing methods in a hospital setting. Further work is needed to refine and psychometrically evaluate instruments for measuring PAS.

\section{Strengths and limitations of this study}

This scoping review is the first to assess (1) the relationship between nurses' expert opinion of staffing adequacy and outcomes, (2) factors influencing nurses' perceived adequacy of staffing, and (3) the reliability and validity of instruments measuring perceived adequacy of staffing.

- The literature search was extensive, and designed and conducted with the help of a clinical librarian.

- Study selection, data extraction and quality appraisal of included studies and instruments were performed by two researchers.

- Limitations of this review include the potential that we have missed original literature on influencing factors or outcomes, because we excluded grey literature and qualitative studies.

\section{INTRODUCTION}

Since the early 1970s, both researchers and practitioners have been searching for the best way to match demand for nursing work with nursing supply. Societal developments have made adequate staffing more relevant today than ever. Driven by an ageing population and technological progress, demand for care is rising. At the same time, the WHO expects a worldwide shortage of over 7 million nurses and midwives by $2030,{ }^{1}$ putting continued pressure on staff. Previous research has indicated an association between nurse staffing levels and nurse-sensitive outcomes such as mortality, adverse events, fall rates, failure-torescue and missed care. ${ }^{2-4}$ Inadequate staffing is also related to burn-out and job dissatisfaction among nurses. ${ }^{5}$ Not only quantity but also quality in terms of skill mix matters; a higher proportion of registered nurses (RNs) is associated with better outcomes. ${ }^{6} 7$ Inadequate staffing ultimately threatens safety, quality, affordability and accessibility of 
care. Therefore, a thorough understanding of staffing adequacy is needed.

The concept of adequacy of staffing can be divided into 'staffing' and 'adequacy'. 'Staffing' has been defined in multiple studies. Jelinek and Kavois ${ }^{8}$ defined nurse staffing as the process of determining the appropriate number and mix of nursing resources necessary to meet workload demand for nursing care at the unit or departmental level. Burke $e t a t^{\theta}$ described hospital staffing as determining the number of personnel with the required skills to meet predicted requirements. Both of these definitions include balancing demand for nursing work with the adequate number and skill mix of nurses. Adding the word 'adequacy' to the concept of staffing, the meaning shifts from the process of staffing to a condition in which staffing is adequate. The American Nurse Association defined staffing adequacy as a match between RN expertise and recipient needs within the practice setting, ${ }^{10}$ but details on what this match entails were omitted. Kramer and Schmalenberg ${ }^{11}$ asked nurses if their staffing was adequate and received ambiguous answers: 'That depends - adequate for what? Safe care to all patients? (...) Quality care? (...) Or comprehensive care?' (p.194).

In the absence of an explicit clarification of what adequate staffing means, ${ }^{12}$ nurses and managers continue to search for staffing measures that can objectify staffing requirements. ${ }^{13}$ These measures need to facilitate different inter-related staffing decisions, for example, how many nurses to employ, staff-shift schedule, nurse roster and nurse-ward allocation. ${ }^{14}$ Many workload and resource planning tools are available related to demand for nursing work, resource planning and workload evaluation.

\section{Demand for nursing work}

Demand for nursing work has been estimated by a volume-based approach, that is, patient counts multiplied by an administrative measure of work. This has been expressed as the nursing hours per patient day (HPPD) ${ }^{15}$ nurse-to-patient ratios ${ }^{2}$ and full-time equivalent numbers. ${ }^{4}$ These have been criticised as measures for staffing decisions because different patient needs are ignored. ${ }^{16}$ The workload-based approach takes different patient care requirements into account and is categorised into activity-based and dependency-based methods. ${ }^{17}$ The activity-based method is based on how long nursing tasks take and the dependency-based method relies on patient classification of patients' needs based on indicators, based on which the amount of nursing time can be derived. Disadvantages of the workload-based approach include lack of reliability, validity and flexibility, and the need for time-consuming manual registration. ${ }^{17-19}$

\section{Resource planning tools}

Other resource planning tools indirectly measure adequacy of staffing by quantifying demand and supply. One example is the RAFAELA patient classification system. ${ }^{20}$ It estimates optimum levels of nursing intensity by balancing demand for care with nursing resources available. The tool is used on a large scale in Finland, but preimplementation in the Netherlands encountered issues of validity and acceptability. ${ }^{21}$

\section{Workload evaluation tools}

Other workload tools evaluate nurses' workload. Tools to evaluate workload can be objective indirect measures of mental workload, such as brain activity and cardiac responses, or subjective tools such as the NASA Task Load Index and the Subjective Workload Assessment Technique. ${ }^{22}$ These subjective instruments involve short questionnaires with items that reflect experiences (eg, mental demand, physical demand, temporal demand). Those type of measures are commonly used to evaluate workload or validate measures of staffing requirements, ${ }^{13}$ reflecting on a broader definition than adequacy of staffing.

In 2010, Fasoli and Haddock ${ }^{18}$ reported reliability and validity issues with the available workload measurement systems. Nine years later, another review ${ }^{13}$ concluded that available systems were still highly uninformative. Scientists dispute whether nursing work can be accurately quantified. Hughes ${ }^{23}$ states that 'it appears that nursing is more concerned with knowledge processing and nurses' intentions than just with the activities of caring' (p.317). Griffiths $e t a l^{13}$ describe that 'there is a limit to what can be achieved through measurement, both because of the fallible nature of the measures, but also because of the complex judgements that are required' (p.9). In the absence of applicable tools, professional judgement was identified as the nearest to a gold standard workload measurement. ${ }^{13}$

\section{Professional judgement}

The match between nurse demand and supply can be measured using the nurses' perceived adequacy of staffing (PAS). This measure relies on nurses' expert opinion in which nurses take the unquantifiable fluctuating patient needs and context and situation into account in assessing adequacy of staffing. ${ }^{24}$ This direct approach to measuring adequacy of staffing contrasts traditional tools that measure staffing adequacy according to demand and supply. Nurses' perceptions have been accepted as a significant indicator of quality of care, ${ }^{2}$ while nurseperceived quality of care was highly associated with objectively measured nurse-sensitive outcomes, showing the validity of the measure. ${ }^{25}$ Regarding nurse staffing tools, relying on nurses' perceptions is less common as most approaches attempt to objectify staffing needs. ${ }^{13}$ However, a reliable and valid measure of PAS may be the optimal approach to helping head nurses and managers make nurse staffing decisions. A positive association of PAS with outcomes for patient, staff and organisation enables evidence-based staffing decision making. Staffing adequacy can potentially be predicted by associating structure and process factors of PAS. Data science techniques may minimise nurse effort by analysing these 
factors in hospital information systems. However, these techniques have not been explored in nurse staffing literature. ${ }^{26} 27$

The concept of PAS potentially enhances nurse staffing methods, going beyond traditional workload measurement or workforce planning tools.

To explore this alternative to objective workload measurement tools, we conducted a scoping review to study the potential relevance of nurses' PAS in the setting of hospital wards. We asked the following research questions:

1. How is PAS associated with outcomes for the patient, nurse and organisation?

2. Which factors influence PAS?

If these findings show PAS to be a potentially relevant measure for a new staffing method, we will go on to answer the following research questions:

3. Which PAS measurement instruments are available in the literature?

4. What is the reliability and validity of those instruments?

\section{METHODS}

We followed the Preferred Reporting Items for Systematic Reviews and Meta-Analyses-Extension for Scoping Reviews checklist and guidelines to ensure our review was robust and replicable. ${ }^{28}$ We did not publish a protocol for this review.

\section{Search strategy}

PubMed, CINAHL, Business Source Complete (through EBSCOhost) and Embase were searched from inception to November 2019. The following free-text and database subject headings were combined to search for peer-reviewed articles: nursing staff, nurses, nurse, staffing adequacy, inadequate staffing, staffing inadequacy, adequate staffing, requirements for nursing resources, attitude of health personnel, perception and perceive, and truncation symbols, for example, nurs*, were used if suitable. Additionally, we screened reference lists of included studies and reviews on nurse staffing for other relevant studies. No limits regarding publication status, date or language were imposed. The complete search strategy for each database is presented in online supplemental appendix 1 . The search was designed and conducted with the help of a clinical librarian.

\section{Study selection}

References from the databases were combined and downloaded into a reference manager, and duplicates were removed. Articles were screened in two phases. First, two reviewers (CM and $\mathrm{CO}$ ) independently screened all titles and abstracts and selected articles that met the inclusion criteria (table 1). For the measurement instruments that were applied, the primary development and evaluation study was included. The screening resulted in a Cohen's $\kappa$ of 0.80. Disagreements about inclusion of studies between the two reviewers ( $\mathrm{CM}$ and $\mathrm{CO}$ ) were resolved by discussion. Next, full-text versions were independently screened by the two reviewers and excluded if articles did not meet the inclusion criteria (table 1). Authors were contacted for irretrievable articles.

\section{Data extraction}

Data were independently extracted by two reviewers (CM and $\mathrm{CO}$ ) using a predefined, structured data abstraction form. The form included the author, year of publication, country, journal, aim, research design, population, test setting, sample size, staffing measures, instruments (including subscales), measurement type, validity, reliability, associations between PAS and outcomes, and associations between influencing factors and PAS. Full details of associations were documented and expressed as correlation coefficients $(r), \beta$-coefficients $(\beta)$ derived from linear regression analysis or ORs derived from logistic regression analysis, including their $\mathrm{p}$ values and 95\% CIs. We also documented whether the associations were corrected for other factors by multivariate analysis.

\section{Quality assessment}

Quality of the study outcomes associated with PAS and the factors influencing PAS were evaluated according to the National Institute for Health and Care Excellence quality appraisal checklist for quantitative studies reporting correlations and associations, ${ }^{29}$ adapted from Griffiths et al. ${ }^{3}$ The checklist assesses bias across four categories-population, confounding factors, measures and analyses-using five response options $(++,+,-$, not reported, not applicable). The resulting score indicates whether the external validity (ie, the generalisability) and the internal validity (ie, the validity of the associations) are strong, moderate or weak.

The methodological quality of the included PAS instruments was appraised using the COnsensus-based
Table 1 Inclusion and exclusion criteria for primary screening

\section{Inclusion}

Studies including front-line nurses in hospitals

\section{Exclusion}

Systematic reviews, qualitative studies, columns, newspaper or opinion articles, conference abstracts

Studies using PAS to evaluate nurse staffing

Studies developing or evaluating an instrument for measuring PAS

PAS, perceived adequacy of staffing. 
Standards for the selection of health Measurement INstruments (COSMIN) Risk of Bias checklist. ${ }^{30} 31$ This checklist, which has been developed to assess the methodological quality of patient-reported outcome measure studies, is suitable for assessing the risk of bias of PAS instruments. Instrument development, structural validity, internal consistency and other measurement properties in the included studies were assessed. Quality was judged as very good, adequate, doubtful or inadequate, and the overall quality was the lowest item rating in the COSMIN boxes. ${ }^{31}$ Measurement properties were rated sufficient $(+)$, insufficient (-) or indeterminate (?) following the criteria for good measurement properties. ${ }^{31}$

Quality was appraised by one reviewer (CM) and crosschecked by a second reviewer (CO). Disagreements between reviewers were solved by consensus.

\section{Data analysis}

Outcomes for each research question were summarised. With regard to the influencing factors and outcome studies, variables analysed by t-tests, (multivariate) analysis of variance ((M)ANOVA), $\chi^{2}$, correlation or regression were judged significant if the value of $p$ was $<0.05$ or their CI did not enclose the value of 0 or 1 . We judged the structural validity and internal consistency of measurement instruments based on the original development study.

\section{Data synthesis}

Data for outcomes/influencing factors and measurement instruments were structured separately. The structure-process-outcome model ${ }^{32}$ was used to structure the influencing factors and outcomes. Influencing factors are factors related to (1) Structure, that is, the physical and organisational context of care delivery, and (2) Process, that is, the technical and interpersonal process of care delivery. Outcomes reflect the impact of those factors demonstrating the result of structure and process. Following the patient care delivery model,$^{33}$ the influencing factors and outcomes of PAS were clustered into patient, staff and organisation categories. Models including PAS as a dependent variable are described separately.

Both single-item and multi-item measurement instruments were included.

\section{Patient and public involvement}

No patient was involved.

\section{RESULTS}

\section{Study selection and characteristics}

The search identified 3120 studies. After removing duplicates and screening titles and abstracts, 135 eligible studies were included for full-text review, including 6 studies that were identified in the reference lists of included studies. Full-text review excluded a further 59 studies. The main reasons for exclusion were no instrument development or associations with influencing factors or outcomes (24/59), no measurement of PAS (10/59) and staffing measures that were not PAS (8/59). For 13 studies, the full text was not available and the authors did not respond to our request for the full text. In total, 63 studies were included in the analysis (figure 1).

The included studies (tables 2 and 3) were published between 1975 and 2019 worldwide. Most studies (28/63) were carried out in North America, ${ }^{11}{ }^{2434-59} 25$ studies were conducted in Europe,${ }^{60-84} 5$ in Asia,${ }^{85-89} 4$ in Oceania ${ }^{90-93}$ and 1 in multiple continents. ${ }^{94}$

Fifty-two studies included outcomes influenced by PAS or factors that influence PAS. ${ }^{24} 35373940$ 42-47 49 52-54 56-60 6263 65-94 Twenty-one studies described the development and evaluation of PAS instruments. ${ }^{11} 3436384143444648505154-5658616482868791$ Forty-nine studies used a cross-sectional research design, ${ }^{24} 3537394042-4752-54565759606263$ 65-76 78-94 two studies used a longitudinal research design ${ }^{49} 77$ and one study used a cross-sectional and longitudinal design. ${ }^{58}$ Complete extracted outcomes and influencing factors are provided in online supplemental appendix 2.

\section{Quality assessment of studies investigating influencing factors and outcomes}

The methodological quality of most studies was moderate to good (table 4). We revealed serious methodological flaws (weak internal and external validity) in six studies. The risk of bias was increased by cross-sectional research designs, omitting confounding factors, and the lack of multilevel studies and objective measures. External validity was weak because the source population was not clearly described and because of the use of single sites. An overview of the compete quality appraisal is presented in online supplemental appendix 3.

\section{Outcomes influenced by PAS}

Our first research question was to explore the associations between PAS and outcomes for the patient, nurse and organisation. Sixty outcomes were found to be influenced by PAS- 27 of these were patient-related, 26 were nurserelated and 7 were organisation-related (table 2). Job satisfaction was investigated in nine studies, ${ }^{39} 4647526672757886$ quality of care in eight studies, ${ }^{3547667275858694}$ safety in four studies, ${ }^{71} 737577$ and missed care, ${ }^{40687}$ emotional exhaustion, ${ }^{66} 6875$ and occupation dissatisfaction ${ }^{39} 5275$ in three studies. Forty-nine outcomes were investigated in two or fewer studies. Most outcomes were positively associated with PAS.

Associations with PAS were found for the patient outcomes pain, ${ }^{84}$ pressure ulcers ${ }^{24}$ and patient-centred care. ${ }^{60}$ Williams and Murphy ${ }^{44}$ asked nurses to rate 10 aspects of care, (including basic hygiene, feeding and medication) from poor to good in six units. Scores for each category were generally higher when staffing was adequate, but results were inconsistent within individual units. Patient safety associated positively with PAS in all studies $^{71} 7377$ except for one, ${ }^{75}$ which reported mixed 


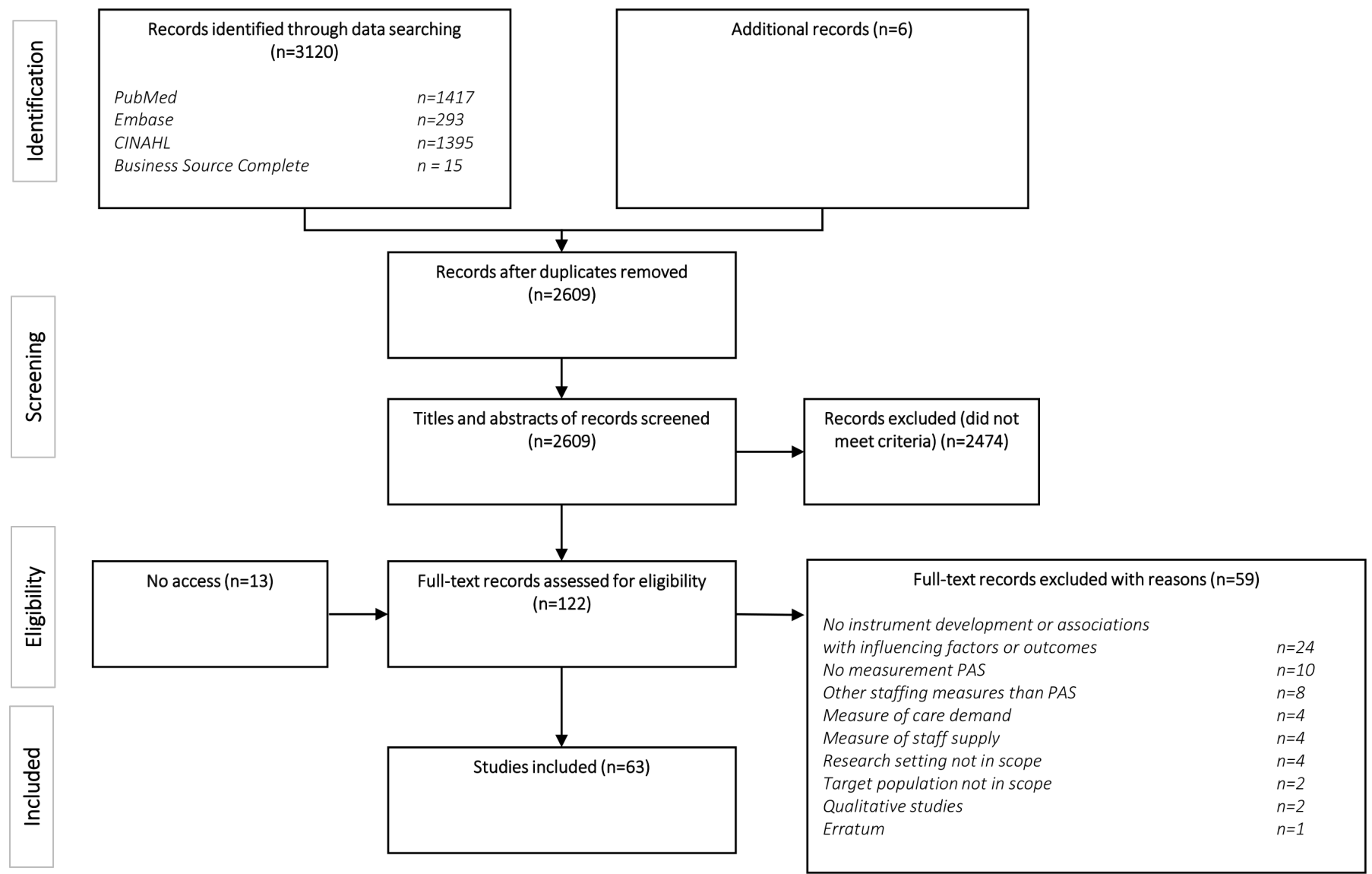

Figure 1 Flow diagram of the search and selection process.

results. Associations with PAS were also mixed for adverse events, ${ }^{87}$ infections, ${ }^{49}{ }^{74}$ survival, ${ }^{73}$ patients' ability to manage care after discharge,$^{76}$ communication with nurses $^{44} 87$ and missed care. ${ }^{4045} 627087$ Cho et a ${ }^{87}$ found that missed communication and basic care mediate the association between patient-perceived staffing and adverse events and communication with nurses.

PAS had a personal effect on nurses. It affected job satisfaction, ${ }^{39} 4647526672757886$ burn-out, ${ }^{78} 86$ effort-reward imbalance, ${ }^{67}$ depersonalisation, personal accomplishment, ${ }^{68}$ feelings of being a safe practitioner and workplace cognitive failure, ${ }^{77}$ psychosocial attention, ${ }^{75}$ and change efficacy. ${ }^{81}$ The reported effects of satisfaction with the occupation, ${ }^{39} 5275$ intention to leave the occupation,${ }^{76}$ intention to leave employment, ${ }^{80} 868994$ emotional exhaustion, ${ }^{66} 6875$ depressive symptoms, ${ }^{67}$ pain, ${ }^{53}$ blood pressure and total cholesterol level ${ }^{82}$ were inconsistent. Pain in the neck, shoulder, arm, lower extremities and musculoskeletal system ${ }^{53}$ as well as low-density lipoprotein cholesterol levels ${ }^{82}$ and change commitment ${ }^{81}$ were not influenced by PAS.

PAS affected organisational outcomes, including nurses' turnover, ${ }^{42} 47$ absenteeism, ${ }^{45}$ quality of nursing ${ }^{73}$ and quality improved within the last year. ${ }^{75}$ Mixed results were reported for quality of care. ${ }^{3547667275858694}$ Patients' hospital rating was associated with patient-perceived staffing adequacy but not with nurse-perceived staffing adequacy. ${ }^{87}$ Anzai et a $l^{85}$ found no association between PAS and nurses' ability to provide quality nursing care.

\section{Influencing factors of PAS}

For the second research question, we identified the structural and process factors that influence PAS.

\section{Structural factors}

Fifty-two structural factors that influence PAS were identified. These were categorised into demand for care (11 factors), nurse supply (30 factors) and organisation of care delivery (11 factors). The setting type was investigated in seven studies ${ }^{44} 477583849192$ and patients-pernurse in three studies. ${ }^{24} 5987$ The remaining 50 factors were investigated in two or fewer studies. Associations were mainly positive, that is, higher scores on structural factors led to more positive PAS.

With regard to demand for care, no consistent results were found for factors associated with PAS. Inconsistent results were found for census, ${ }^{43}{ }^{44}$ number of maximum care patients ${ }^{43}$ and patient classification category. ${ }^{43} 5869$ New admissions, transfers, discharges, postoperative patients, specialised nursing procedures ${ }^{43}$ and crowding scores in the emergency department ${ }^{54}$ were not related to PAS.

Nurse supply factors influencing PAS were full-time equivalent RNs per patient day, ${ }^{58} \mathrm{HPPD},{ }^{24}$ nursing hours,${ }^{43}$ 


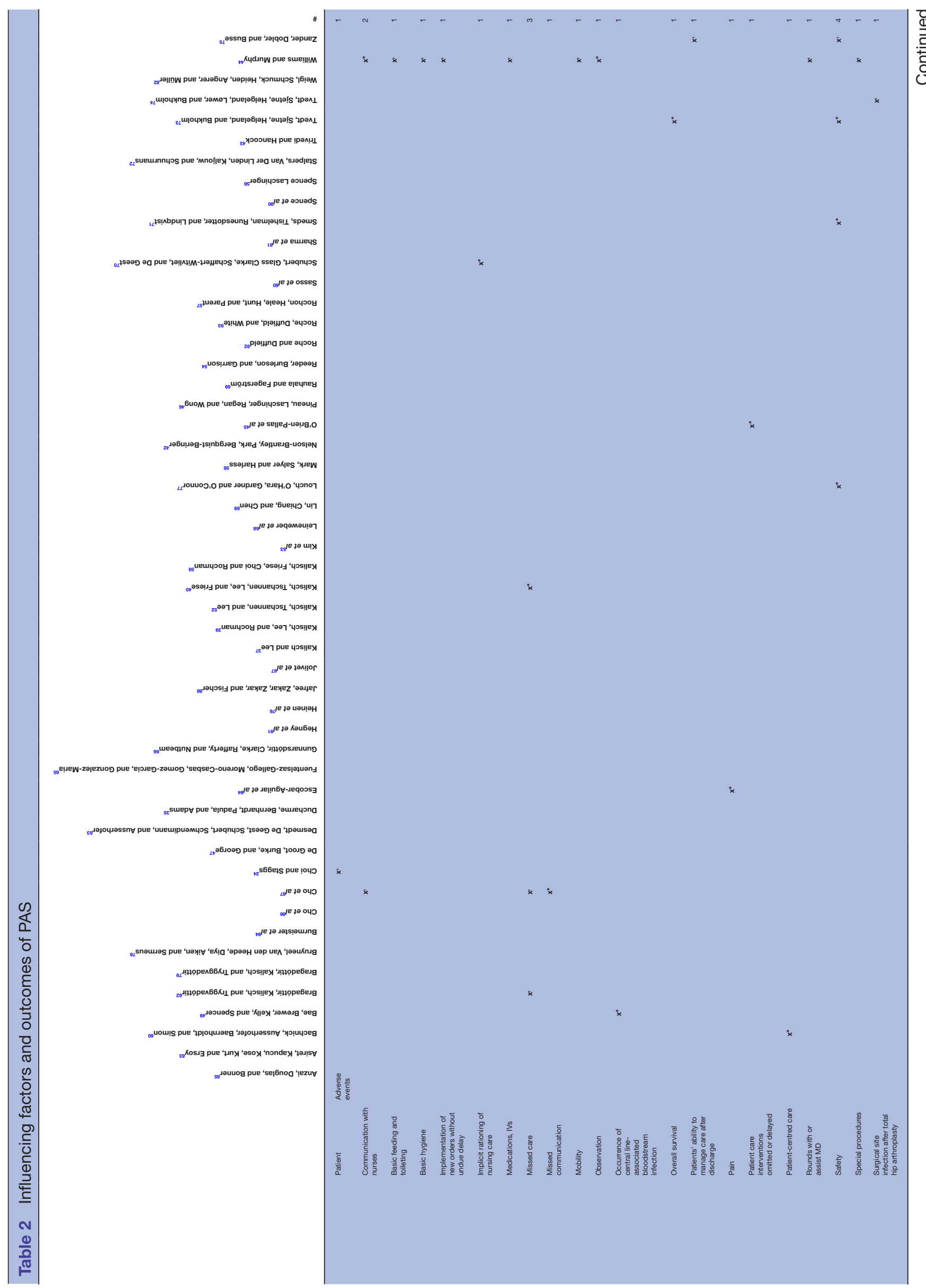




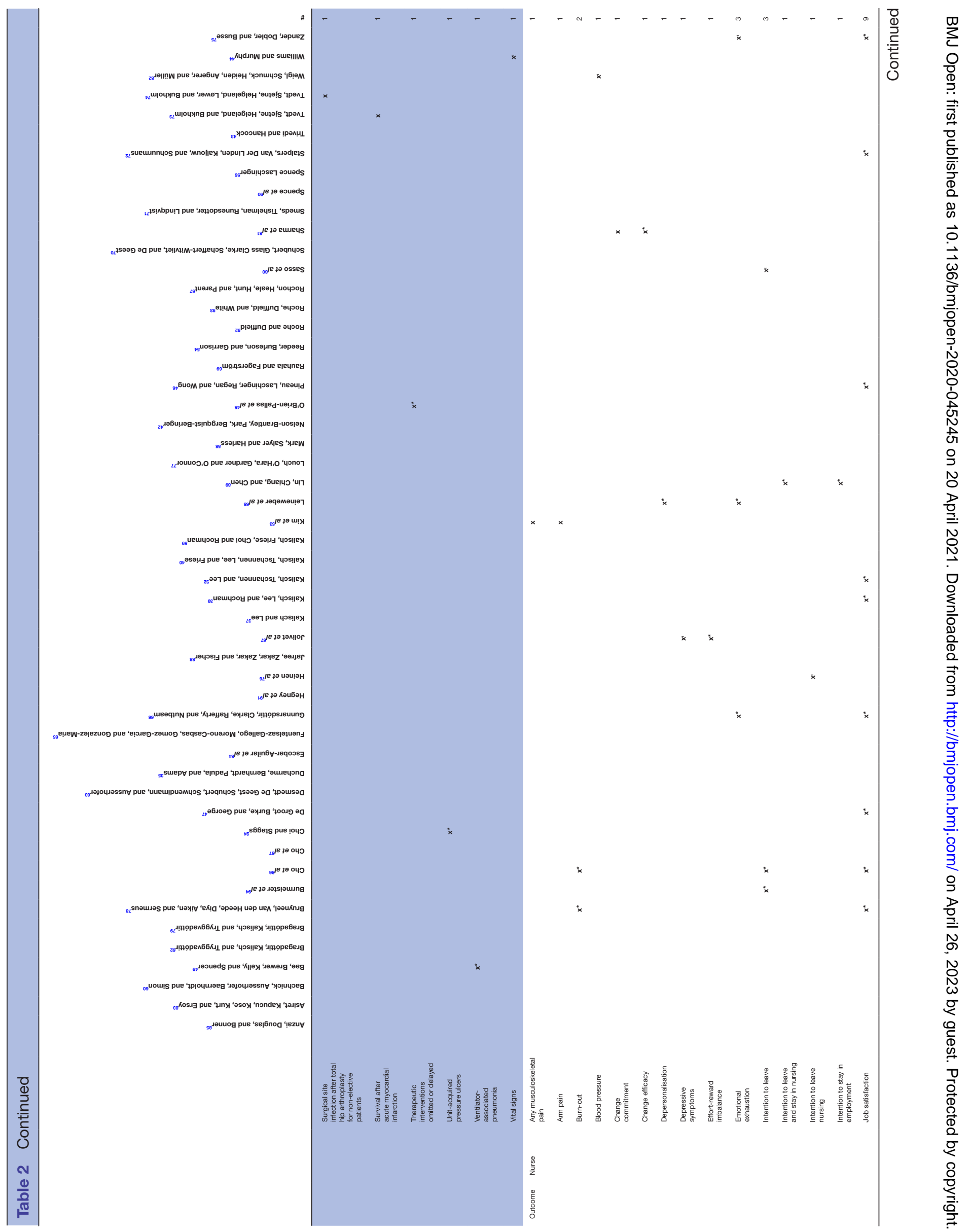




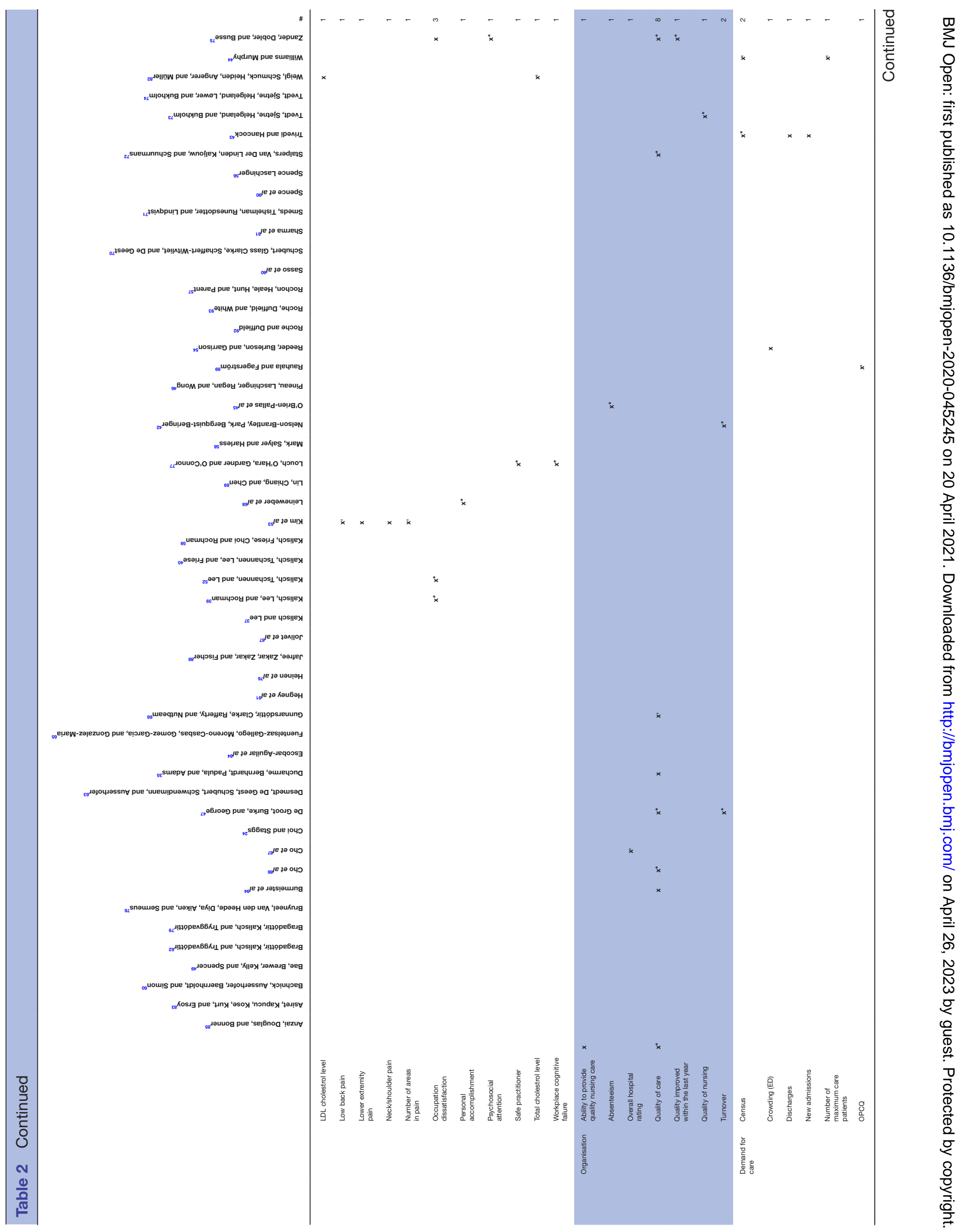




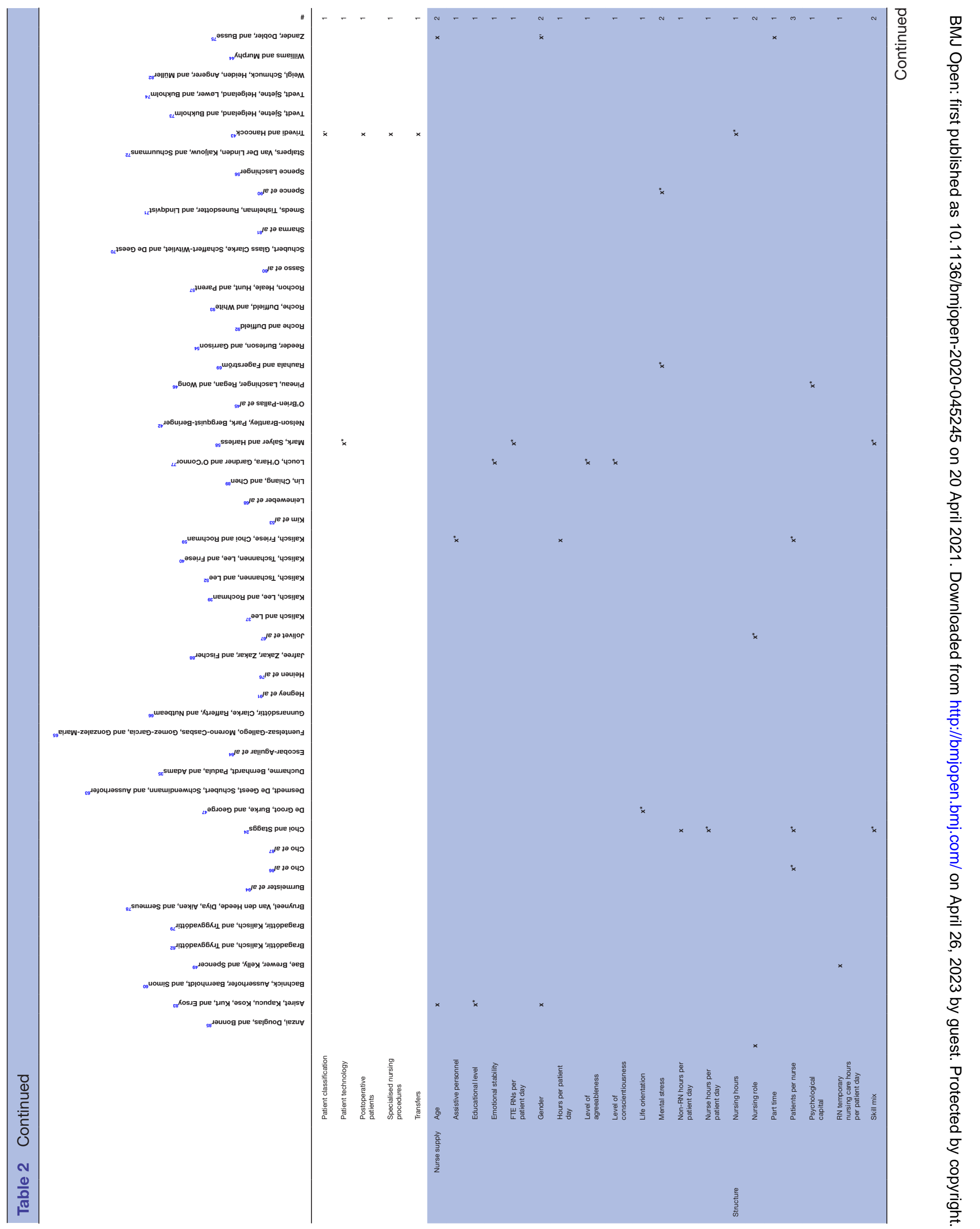




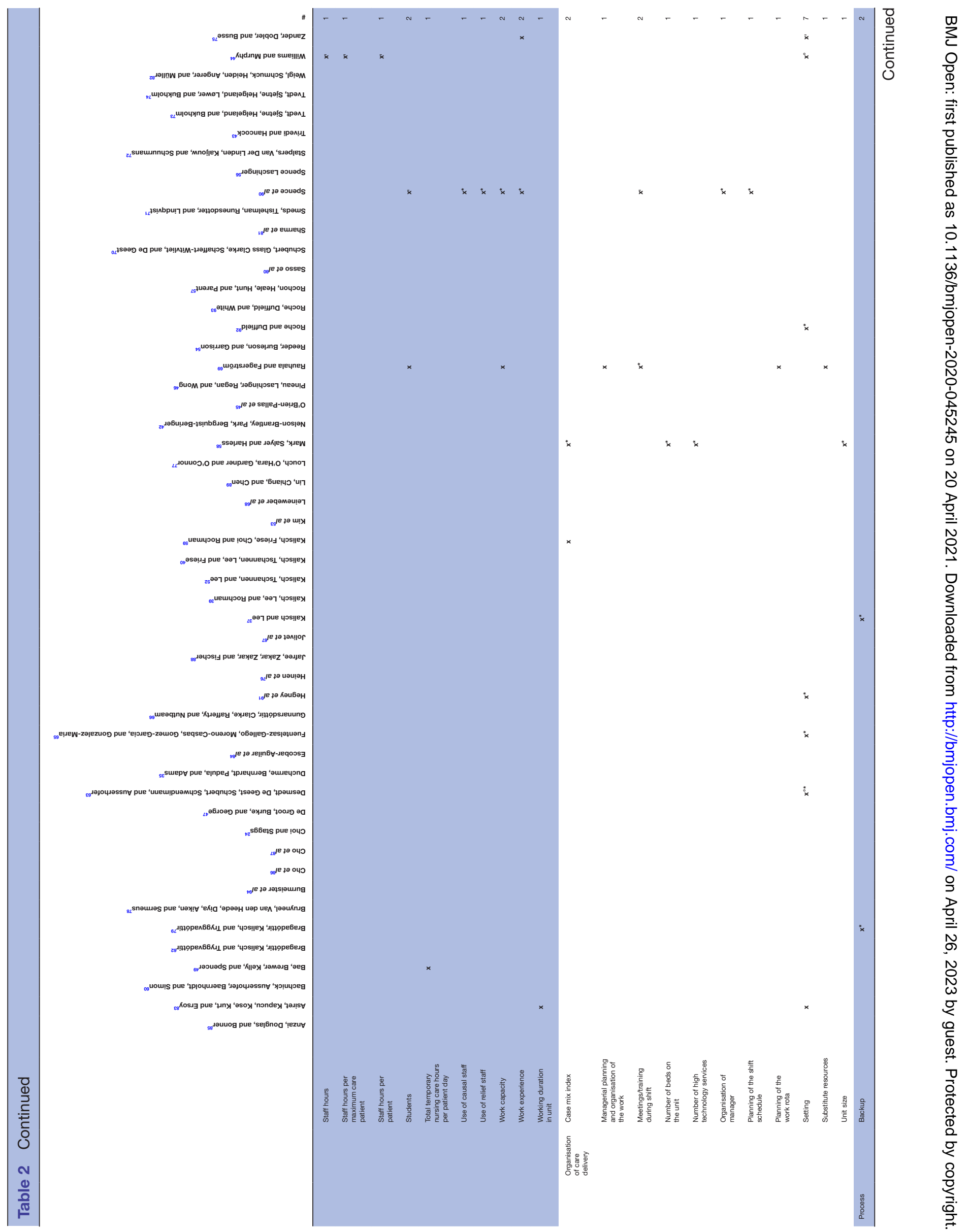




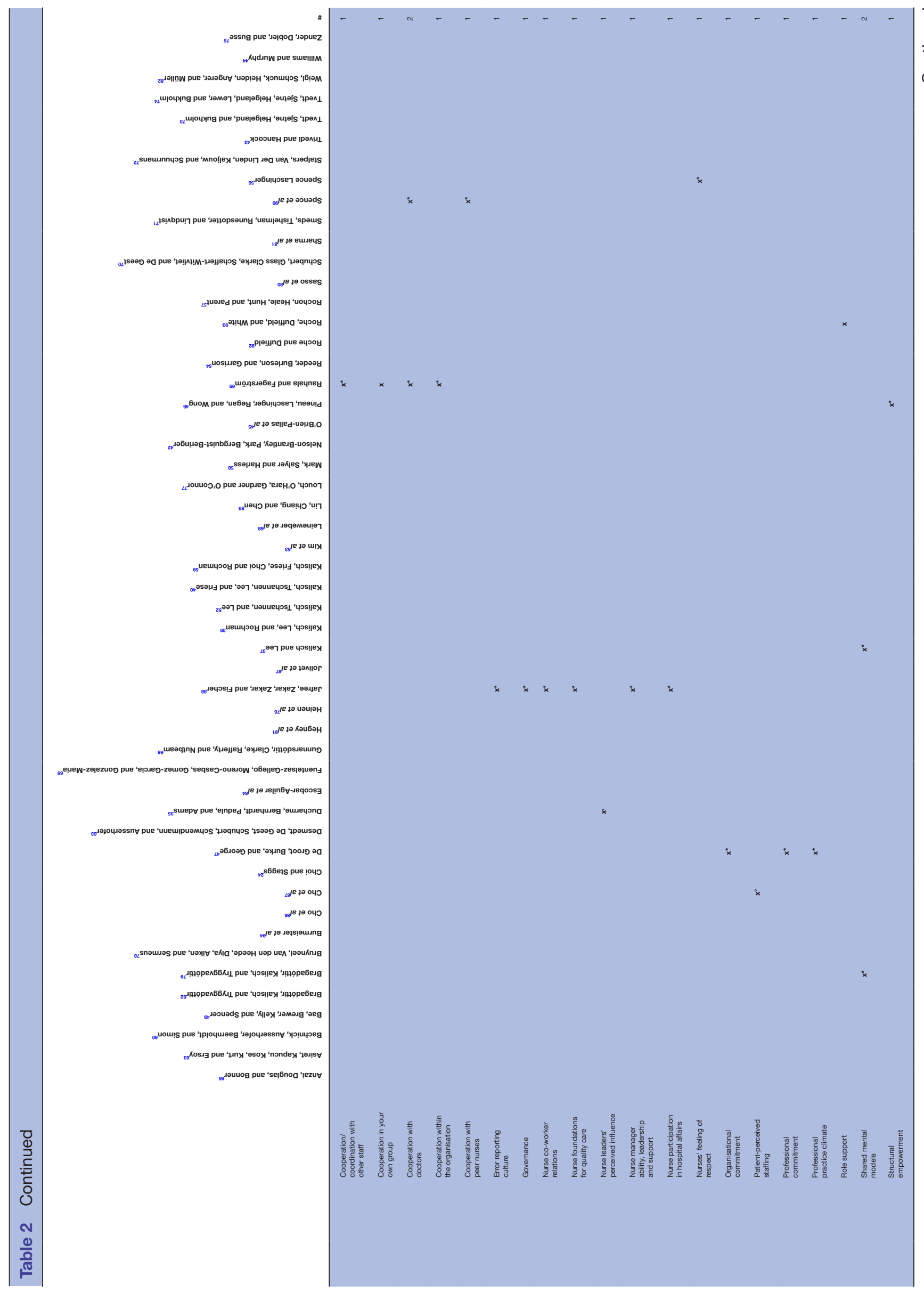




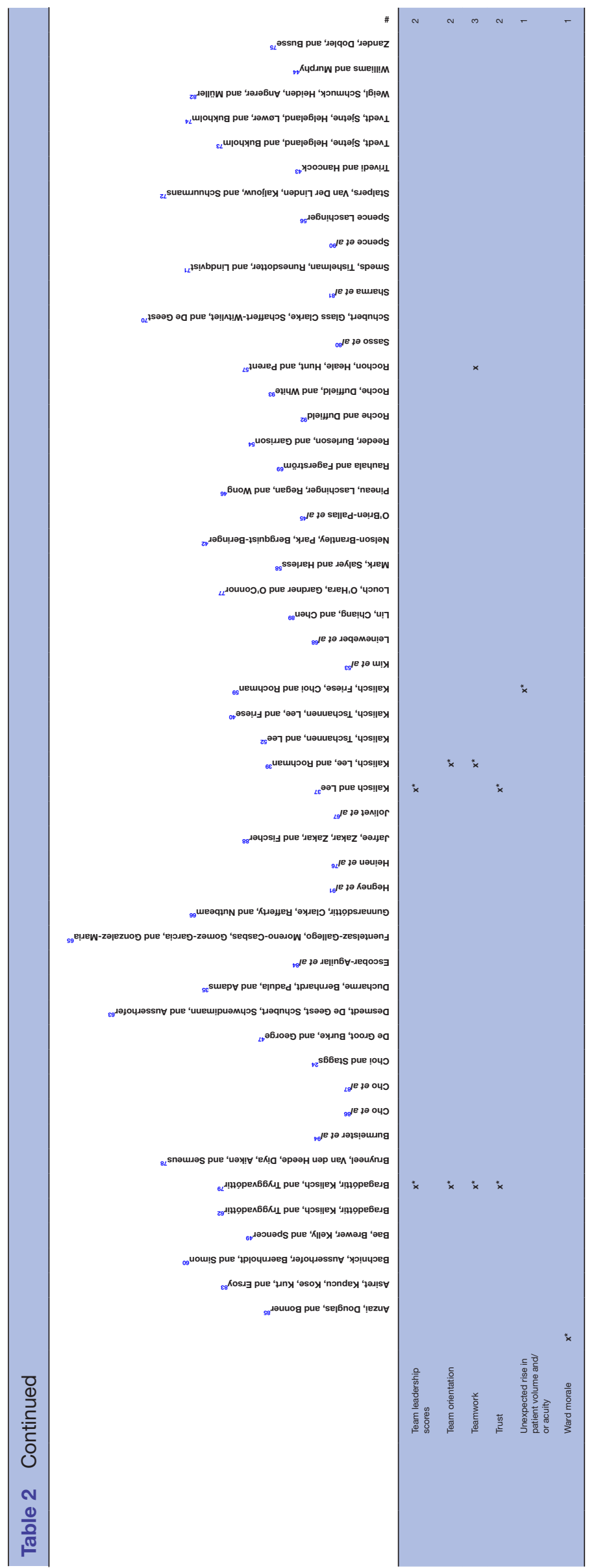




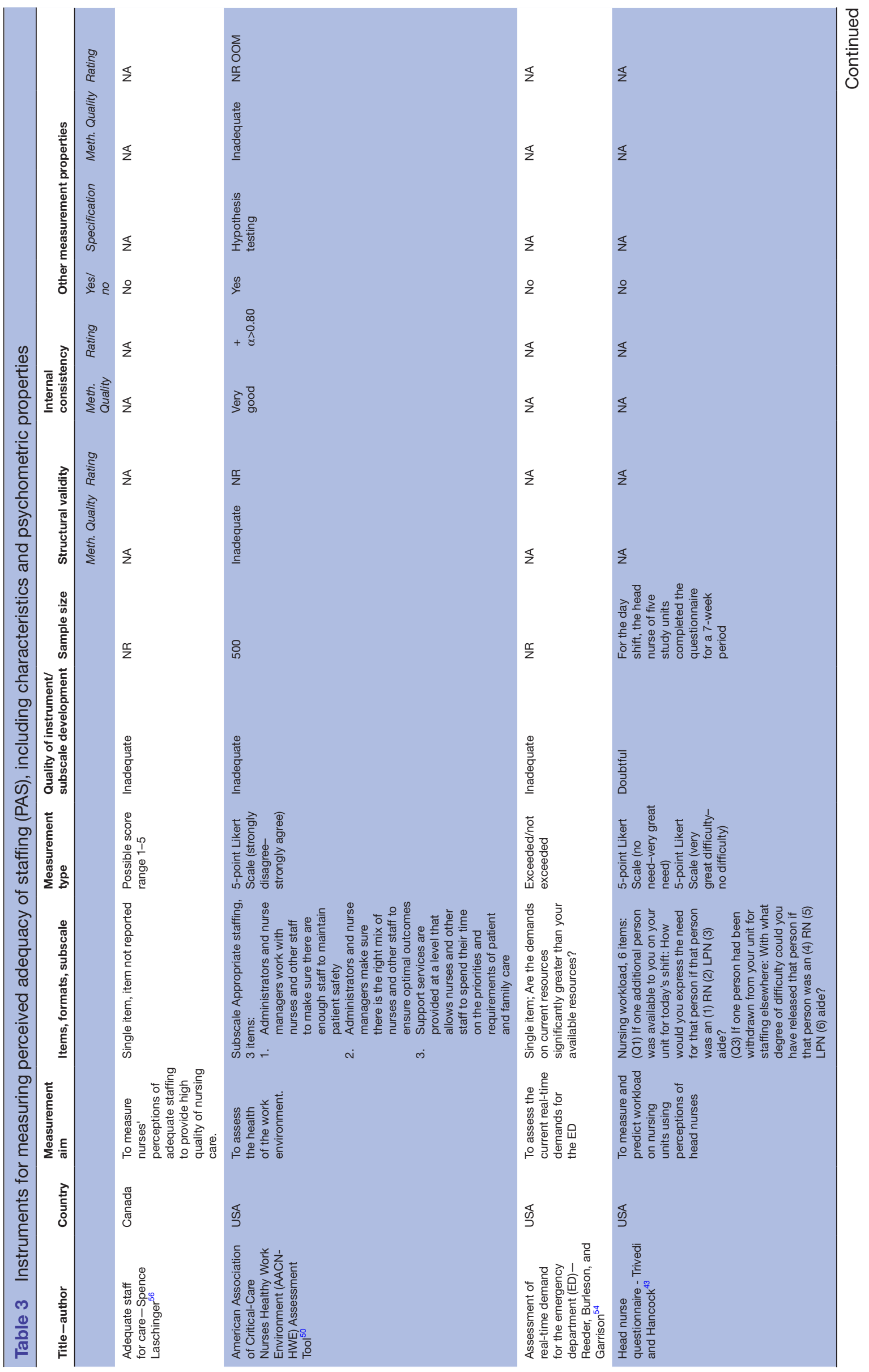

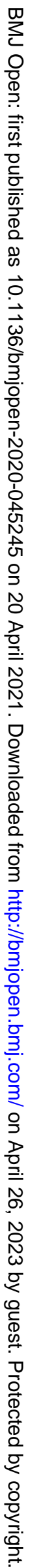




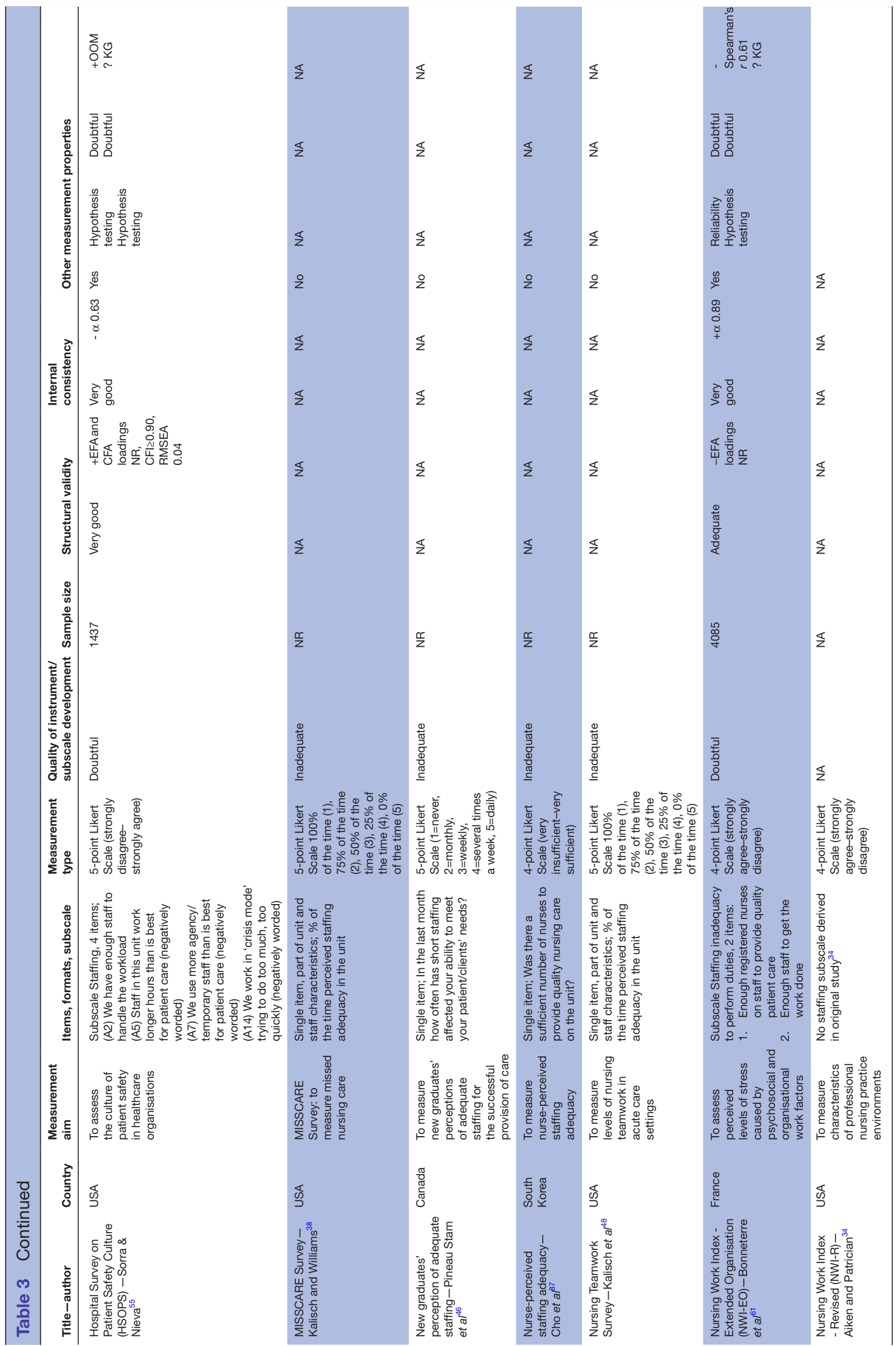




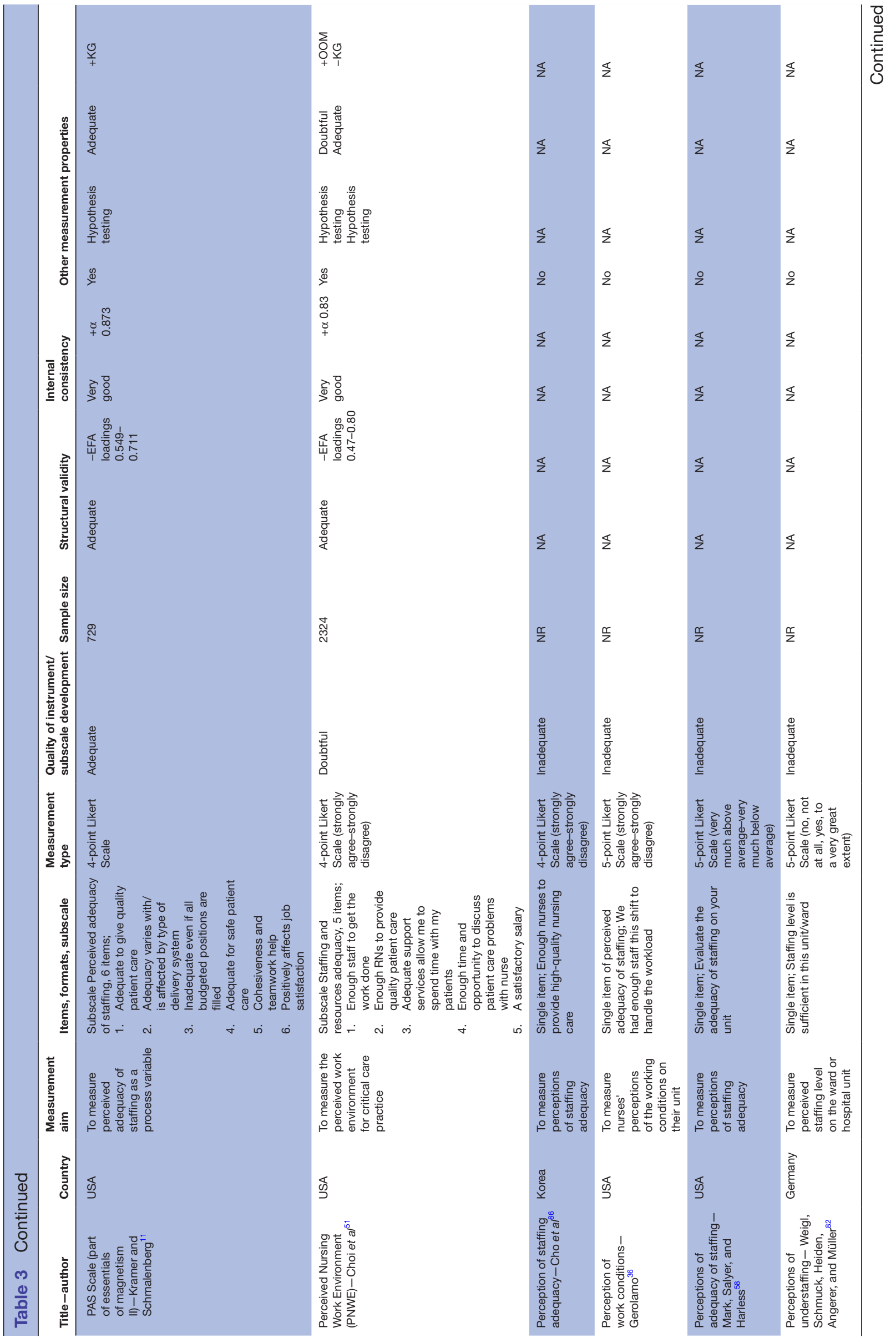

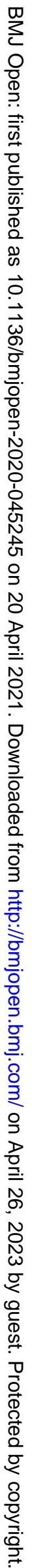



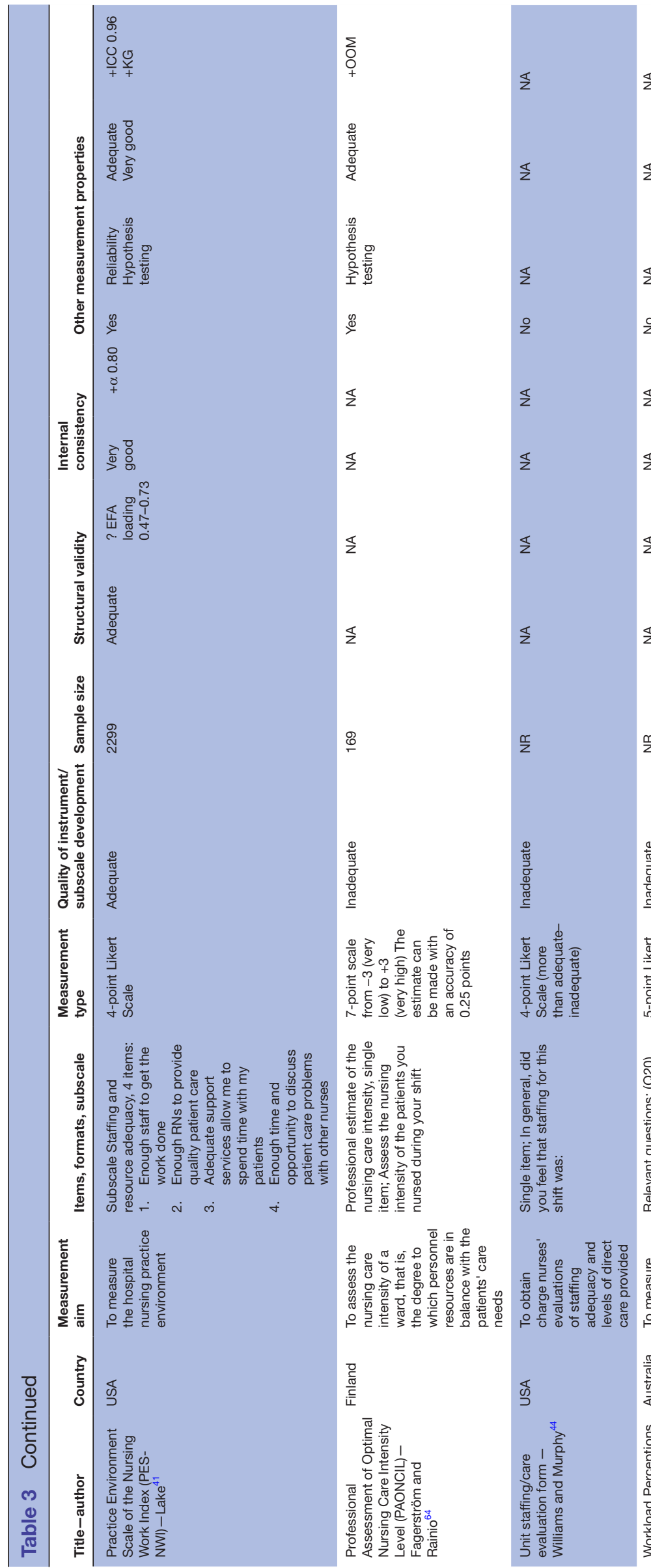

蝑

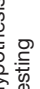

$\frac{s}{2}$

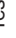

s

$\Sigma$

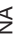

$\frac{s}{z}$

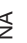

$\frac{s}{z}$

$\Sigma$

$\stackrel{8}{\circ}$

$\frac{n}{2}$

$\frac{\mathfrak{c}}{z}$

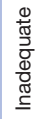

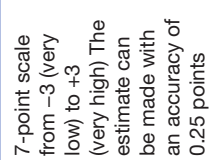

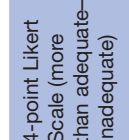

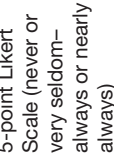

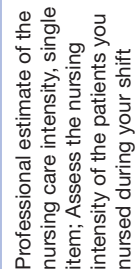

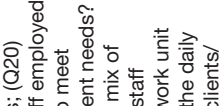

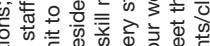

फ़

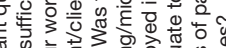

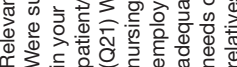

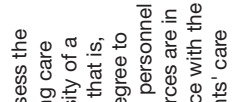
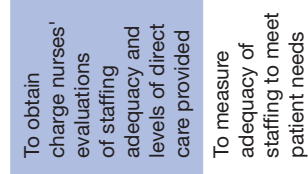

总
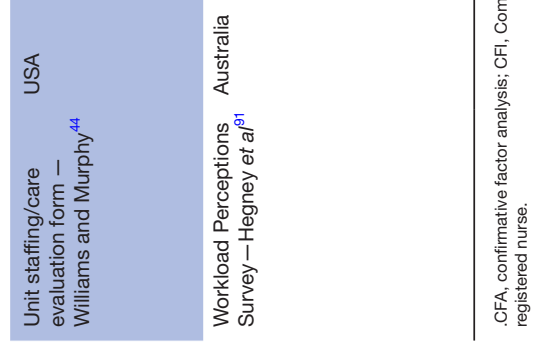
Table 4 NICE quality appraisal checklist ${ }^{29}$ adapted from Griffiths et a/ ${ }^{3}$

\begin{tabular}{|c|c|c|c|}
\hline Criteria & Weak & Moderate & Strong \\
\hline \multicolumn{4}{|l|}{ Section 1: Population } \\
\hline 1.1 Is the source population or source area well described? & $15 \% \quad(8)$ & $42 \%$ & $42 \% \quad(22)$ \\
\hline 1.3 Do the selected participants or areas represent the eligible population or area? & $8 \% \quad(4)$ & $50 \%$ & $42 \% \quad(22)$ \\
\hline \multicolumn{4}{|l|}{ Section 2: Confounding factors } \\
\hline \multicolumn{4}{|l|}{ Section 3: Measures } \\
\hline 3.1 Were the main measures and procedures reliable? & $2 \%$ & $85 \%$ & $13 \%$ \\
\hline 3.2 Were the outcome measurements complete? & $0 \%$ & $50 \%$ & $50 \% \quad(26)$ \\
\hline \multicolumn{4}{|l|}{ Section 4: Analyses } \\
\hline 4.0 Study design and analyses & $92 \% \quad(48)$ & $8 \%$ & $0 \%$ \\
\hline 4.3 Was the precision of association given or calculable? Is association meaningful? & $8 \%$ & $19 \%$ & $73 \% \quad(38)$ \\
\hline \multicolumn{4}{|l|}{ Section 5: Summary } \\
\hline 5.1 Are the study results internally valid (ie, unbiased)? & $27 \% \quad(14)$ & $40 \%$ & $33 \% \quad(17)$ \\
\hline 5.2 Are the findings generalisable to the source population (ie, externally valid)? & $15 \%$ & $37 \%$ & $48 \% \quad(25)$ \\
\hline
\end{tabular}

NICE, National Institute for Health and Care Excellence.

patients-per-nurse, ${ }^{24} 5986$ (RN) skill mix, ${ }^{24}{ }^{58}$ educational level, ${ }^{83}$ assistive personnel, ${ }^{59}$ causal/relief staff, ${ }^{90}$ mental stress, ${ }^{69} 90$ nurses' psychological capital ${ }^{46}$ and life orientation. ${ }^{47}$ Mixed results were reported for staff hours available, ${ }^{44}$ presence of students, ${ }^{69} 90$ nursing role, ${ }^{6785}$ gender ${ }^{7585}$ work experience ${ }^{758390}$ and nurses' work capacity. ${ }^{69} 90$ Nursing HPPD, non-RN HPPD, ${ }^{24} 59$ temporary nursing-care HPPD, ${ }^{49}$ age $^{7583}$ and part-time nurses ${ }^{75}$ were not related to PAS. Louch et $a l^{77}$ found that levels of agreeableness and conscientiousness moderated the association between PAS and whether nurses feel they can act as a safe practitioner, and that emotional stability moderated the association between PAS and patient safety.

Organisation of care delivery factors unit size, number of beds and number of high-technology hospital services ${ }^{58}$ affect PAS. Spence $e t a l^{00}$ reported that organisation of the clinical manager's work and the shift schedules was the most important of nine factors that increase workload. In contrast, Rauhala and Fagerström ${ }^{69}$ found no relationship between managerial planning, work organisation, work rota planning and Professional Assessment of Optimal Nursing Care Intensity Level (PAONCIL) Scores. Mixed results were found for the setting, ${ }^{44} 477583849192$ case mix index ${ }^{58} 59$ and meetings and training during shifts. ${ }^{69} 90$ Substitute resources did not correlate with PAONCIL Scores. ${ }^{69}$

\section{Process factors}

Twenty-seven process factors were investigated in relation to PAS. Most process factors were positively associated with PAS, that is, higher process factor values were related to more positive PAS.

Teamwork was investigated in three studies, and other factors were examined in two or fewer studies. Ward morale ${ }^{85}$ error reporting culture, governance, nurse participation in hospital affairs, nurse manager ability, leadership and support, foundations for quality nursing care, ${ }^{88}$ trust, shared mental models, team leadership, backup, ${ }^{37} 79$ structural empowerment ${ }^{46}$ nurses' feeling of respect, ${ }^{56}$ organisational and professional commitment, professional practice climate, ${ }^{47}$ and unexpected rise in patient volume or acuity, ${ }^{59}$ all influenced PAS. An increase in positive patient perceptions of staffing was related to an increase in positive perceptions of nurse staffing. ${ }^{87}$ Intraprofessional and interprofessional cooperation 69890 and teamwork ${ }^{375779}$ showed inconsistent associations with PAS. The perceived influence of nurse leaders was associated with PAS in four out of six leadership domains. ${ }^{35}$ PAS was not associated with role support. ${ }^{93}$

\section{Models}

Three studies explained PAS using regression models. Kalisch et $a \tilde{\nu^{9}}$ reported four different models with variables HPPD, case mix index, nursing education, unexpected rise in patient volume and acuity, and inadequate number of assistive personnel. The model including all variables explained most variance in PAS (33.8\%). Mark et $a \tilde{l}^{8}$ studied three models explaining between $33 \%$ and $51 \%$ of the variance in PAS. Patient technology, number of beds, growing admissions, and case mix index were relevant in all three models. Rauhala and Fagerström ${ }^{69}$ 
built models for 22 wards including patient classification and non-patient questions as independent variables. The median variance explained by patient factors alone was $45 \%$. Adding non-patient factors increased the median variance to $55 \%$, indicating that patient factors contributed to PAS more strongly than non-patient factors did.

\section{Measurement instruments of PAS}

The third research question investigated instruments used to measure the PAS. We found 21 studies that described PAS measurement instruments (table 3), ${ }^{113436384143444648505154-565861648286879191} 20$ of which were found in the development studies. Most instruments were developed in the last two decades, except for two that were developed in the 1970s. ${ }^{43}{ }^{44}$ Most instruments $(12 / 19)$ were developed in the USA. ${ }^{11} 3436384143444851545558$

The measurement aim, items and response options of the different instruments varied considerably. Instruments with a direct practical purpose of balancing nurse demand and supply were the head nurse questionnaire, ${ }^{43}$ PAONCIL, ${ }^{64}$ assessment of real-time demand for the emergency department ${ }^{54}$ and the unit staffing/care evaluation form. ${ }^{44}$ These instruments are used on a daily basis.

PAS is measured in the different questionnaires by single items, ${ }^{36} 3844464854565864828687$ multiple items ${ }^{4391}$ and multi-item subscales to evaluate safety culture ${ }^{55}$ and nursing work environment. ${ }^{113441505161}$ Some items assess the adequacy of staffing numbers (eg, 'Enough staff to get the work done'), ${ }^{36} 41434651556182868791$ and some assess the skill mix (eg, 'Enough registered nurses on staff to provide quality patient care') ${ }^{414350516191}$ Some instruments attempt to specify the purpose of adequate staffing (eg, adequate 'for quality care', 11415156618687 'to handle the workload', 3655 'to meet your patient/clients' needs', ${ }^{4691}$ 'to get the work done ${ }^{415161}$ and 'to maintain patient safety ${ }^{50}$ ) while other instruments just measure adequacy of staffing without specifying what this entails. ${ }^{3844} 485882$

The target respondents of all instruments are nurses in general, head nurses, ${ }^{43}$ critical care nurses,${ }^{50}{ }^{51}$ charge nurses ${ }^{44}$ or new graduates. ${ }^{46}$ One study asked both nurses and patients to assess PAS. ${ }^{87}$ Most instruments used a 4-point or 5-point Likert Scale. ${ }^{11} 343638414344464850515556586182868791$ Real-time demand for the emergency department ${ }^{54}$ was assessed using a dichotomous scale: exceed or not exceed. The PAONCIL includes a 7-point scale, and estimates can be made with an accuracy of 0.25 points. ${ }^{64}$

\section{Reliability and validity}

The fourth research question assessed the reliability and validity of PAS measurement instruments. We found methodological flaws in most studies. With regard to the singleitem instruments, construct validity of PAONCIL was tested by hypothesising a correlation between PAONCIL scores and patient classification scores. ${ }^{64}$ No other studies of single-item or multi-item measures reported reliability or validity testing. The Nursing Work Index - Revised development study did not use a staffing subscale, ${ }^{34}$ so we could not assess psychometric properties. For the remaining six subscales, ${ }^{11} 4150515561$ the methodological quality of structural validity and internal consistency were adequate, except for structural validity of the American Association of Critical-Care Nurses Healthy Work Environment. However, while internal consistency was sufficient in most studies, structural validity was sufficient in only one study.

\section{DISCUSSION}

Our scoping review found that mostly positive perceptions of staffing adequacy (measured using the PAS) are related to positive outcomes for patient, nurse and organisation, confirming the importance of the measure. We identified many factors that influence PAS, but the associations were inconsistent. Twenty-one instruments were identified that measure PAS, and these different instruments had different measurement aims.

Most studies reported that positive perceptions of staffing adequacy are related to positive outcomes for the patient, nurse and organisation. Effects on patient outcomes were inconsistent, mainly because of severe methodological flaws in one study. ${ }^{44}$ The positive relationship between staffing and outcomes was confirmed by different staffing measures, such as nurse-to-patient ratios. ${ }^{13} 95$ However, studies explained more of the variation in patient outcomes of PAS than staffing measures such as nurse-to-patient ratios and HPPD, ${ }^{2460}$ indicating the informative value. Kalisch $e t a p^{59}$ found moderate correlations between nurse-reported staffing adequacy, nurse-to-patient ratios and nursing HPPD, clarifying that these measures 'may capture different elements of the unit context to explain nurse staffing' (p.775). It seems that adequate staffing depends on more than just staff numbers and skill mix elements, and that nurses take these additional factors into account when assessing PAS. ${ }^{24} 96$ In agreement with this, we identified many factors that influence PAS in the present study, including demand for care, nurse staffing, and organisation and process factors. Whether outcomes are improved by objective measurement of workload on a daily basis is unclear. ${ }^{12}$ The RAFAELA system has provided some evidence that patient safety and mortality are associated with workload level. ${ }^{97}$ Our finding that measuring the PAS is associated with positive outcomes indicates that measuring the PAS will strengthen nurse staffing tools, which will in turn improve staffing decisions. Measuring the PAS was also found to be relevant in research areas other than nurse staffing. For example, PAS was one of the eight essential factors of magnetism. Magnetism refers to elements that are essential for a work environment that can attract and retain nurses while providing a high level of job satisfaction and quality of care. ${ }^{98}$

We identified a variety of factors that influence PAS, but were unable to define a valid set of factors that were relevant to nurse staffing. Most factors were investigated in 
one study and results were inconsistent between studies. There appear to be many factors affecting PAS, including patient-related and nurse-related factors and how care delivery is organised. Factors related to the work environment were also important, such as cooperation, leadership and teamwork. This is in agreement with other studies of factors that influence demand for care ${ }^{99-102}$ Hence, patient, nurse and organisation factors were recommended to consider in a staffing model. ${ }^{101}$ Nurses have disputed traditional instruments for measuring workload because they involve time-consuming manual registration and cannot forecast staffing adequacy. ${ }^{17-19} 96100103$ Including influencing factors in a staffing model can solve these issues, enabling decision makers to align nursing resources in a timely fashion. The study by Trivedi and Warner ${ }^{104}$ was one of the first attempts to predict staffing adequacy using data. They designed a multivariate regression model that predicted head nurse perceptions of staffing adequacy and used this model to allocate float nurses at the beginning of the shift. Nowadays, more advanced techniques are available. Machine learning and artificial intelligence can be used to analyse hospital data and potentially explain and forecast PAS, supporting staffing decisions. These methods are a prerequisite for reliable and valid measurement of PAS.

Most of the PAS measurement instruments we found were single items, and they did not include psychometric testing. However, multiple psychometric tests can be performed on single items, including tests for content validity, inter-rater variability and responsiveness. ${ }^{105}$ Although a single item is suitable in some situations, ${ }^{106}$ multiple items are more reliable. Multiple items should be used for complex constructs as they define the meaning of the construct for the rater. ${ }^{105}$ Kramer and Schmalenberg found that multiple items are needed to measure PAS. ${ }^{107}$ However, the downside of administrative burdens have been shown to inhibit successful implementation. ${ }^{21}$ Most relevant shortcomings of multiple-item instruments of PAS are a lack of information on subscale development, omitting to fully determine structural validity by confirmative factor analysis and confirm other psychometric properties such as reliability, criterion validity, hypothesis testing, measurement error and responsiveness.

Overall, development and evaluation of PAS instruments has been moderate; this reflects the varying use of the measure. There is no established definition of staffing adequacy. Most instruments reflect the adequacy of staff numbers, and some include skill mix (which is becoming increasingly relevant). ${ }^{3108}$ In addition, the measurement aims differ between instruments. For some measurements such as safety $^{55}$ and work environment, ${ }^{3441}$ it is sufficient to grade adequacy of staffing, while for nurse staffing decision making understaffing or overstaffing need to be graded. Moreover, instruments measure PAS by referring to the adequacy of full-time equivalent numbers ${ }^{11}$ or team composition. ${ }^{41}$ This tactical/strategic decision level of staffing differs from instruments on operational decision levels of capacity management, where decisions involve the staff schedule of a specific shift. Just as for workload measurement tools, ${ }^{12}$ the decisions supported by the PAS instrument are mostly unspecified. As a result, there are a variety of available instruments, so practical use of PAS in the nurse staffing process is still limited. Decision makers continue to search for objective staffing measures and rely only moderately on nurses' opinions, so there is still a significant gap between managers and nurses in daily operations.

\section{Strengths and limitations}

The strengths of our review includes that our review was set up systematically and assessed the quality of included studies, something which is not mandatory for a scoping review. ${ }^{109}$ But, there are some limitations to our study. First, we were unable to assess the full text of some studies $(0.5 \%)$ because of no access and failing requests to researchers. However, because of the small amount of inaccessible studies we consider these studies of minimum impact on our results and conclusions. Second, we searched for studies that developed and validated PAS instruments, which could have affected our results as other publications discussing psychometric properties of included instruments were not included. Finally, we excluded qualitative studies and grey literature, which may have included potential influencing factors or outcomes. Because these studies are often followed up by quantitative studies to determine influencing factors, ${ }^{102}$ it is likely that these factors and outcomes already are included in the quantitative studies included in this review. Nevertheless, in future research qualitative data should be explored as an extension of the results reported in this review.

\section{Practical implications}

Adequate staffing is essential for the patient, nurse and organisation. ${ }^{110}$ In an ideal situation, PAS would be evaluated daily on the hospital ward to identify inadequate staffing either at the beginning of a shift or in upcoming shifts. Using existing patient and nurse data avoids additional administrative work and incorporating nurses' judgement potentially generates valid and reliable information acceptable to nursing staff. Measuring PAS in this way is in accordance with existing design principles. ${ }^{101}$ The information is input for a mutual dialogue and decision making on a team, ward or crossdepartmental level. Nursing managers should recognise that staff numbers do not tell the whole staffing story and avoid investing in traditional patient classification systems. Machine learning and artificial intelligence will provide new opportunities for measuring adequacy of staffing in the near future. For adequate and practical measurement of PAS, a balance should be found between using multiple items for reliability and limiting the effort needed to use them. For this to work, practitioners need to be involved in developing adequate PAS measures.

\section{CONCLUSIONS}

This scoping review found that PAS is positively associated with outcomes for patient, nurse and organisation, supporting the relevance of PAS as a measure for 
nurse staffing decisions. Many factors were identified that influence PAS, but associations were inconsistent. Instruments used to measure PAS were found to have moderate reliability and validity. Measuring PAS could enhance nurse staffing methods by predicting staffing adequacy based on existing patient and nurse data using machine learning and artificial intelligence techniques. This approach goes beyond traditional workload measurement or workforce planning methods. Further work is needed to refine and psychometrically evaluate instruments measuring PAS.

\section{Author affiliations}

${ }^{1}$ Department of Capacity Management, Rijnstate Hospital, Arnhem, The Netherlands ${ }^{2}$ Radboud Institute for Health Sciences, Scientific Center for Quality of Healthcare (IQ healthcare), Radboudumc, Nijmegen, The Netherlands

${ }^{3}$ Faculty of Health and Social Studies, HAN University of Applied Sciences, Nijmegen, The Netherlands

${ }^{4}$ Institute for Management Research, Radboud University, Nijmegen, The Netherlands

${ }^{5}$ Erasmus School of Health Policy \& Management, Erasmus University Rotterdam, Rotterdam, The Netherlands

${ }^{6}$ Spaarne Gasthuis Academy, Spaarne Gasthuis Hospital, Hoofddorp and Haarlem, The Netherlands

Acknowledgements The authors thank On Ying Chan, information specialist, Radboud University Medical Center, the Netherlands, for her help with developing and refining the search strategy.

Contributors All authors (CM, HV, PH and $\mathrm{CO}$ ) were involved in planning the scoping review. $\mathrm{CM}$ and $\mathrm{CO}$ were involved in the search strategy, extraction, quality appraisal and synthesis of data, and wrote the first draft of the manuscript. All authors revised the manuscript drafts and approved the final manuscript.

Funding The authors have not declared a specific grant for this research from any funding agency in the public, commercial or not-for-profit sectors.

Competing interests None declared.

Patient consent for publication Not required.

Provenance and peer review Not commissioned; externally peer reviewed.

Data availability statement Data are available in a public, open access repository.

Supplemental material This content has been supplied by the author(s). It has not been vetted by BMJ Publishing Group Limited (BMJ) and may not have been peer-reviewed. Any opinions or recommendations discussed are solely those of the author(s) and are not endorsed by BMJ. BMJ disclaims all liability and responsibility arising from any reliance placed on the content. Where the content includes any translated material, BMJ does not warrant the accuracy and reliability of the translations (including but not limited to local regulations, clinical guidelines, terminology, drug names and drug dosages), and is not responsible for any error and/or omissions arising from translation and adaptation or otherwise.

Open access This is an open access article distributed in accordance with the Creative Commons Attribution Non Commercial (CC BY-NC 4.0) license, which permits others to distribute, remix, adapt, build upon this work non-commercially, and license their derivative works on different terms, provided the original work is properly cited, appropriate credit is given, any changes made indicated, and the use is non-commercial. See: http://creativecommons.org/licenses/by-nc/4.0/.

\section{ORCID iD}

Carmen J E M van der Mark http://orcid.org/0000-0002-7384-5413

\section{REFERENCES}

1 World Health Organization. Health workforce requirements for universal health coverage and the Sustainable Development Goals. (Human Resources for Health Observer, 17) 2016.

2 Aiken LH, Sermeus W, Van den Heede K, et al. Patient safety, satisfaction, and quality of hospital care: cross sectional surveys of nurses and patients in 12 countries in Europe and the United States. BMJ 2012;344:e1717.

3 Griffiths P, Recio-Saucedo A, Dall'Ora C, et al. The association between nurse staffing and omissions in nursing care: a systematic review. Journal of Advanced Nursing 2018;74:1474-87.

4 Kane RL, Shamliyan TA, Mueller C, et al. The association of registered nurse staffing levels and patient outcomes: systematic review and meta-analysis. Medical Care 2007;45:1195-204.

5 Aiken LH, Clarke SP, Sloane DM, et al. Hospital nurse staffing and patient mortality, nurse burnout, and job dissatisfaction. JAMA 2002;288:1987-93.

6 Griffiths P, Ball J, Drennan J, et al. Nurse staffing and patient outcomes: strengths and limitations of the evidence to inform policy and practice. A review and discussion paper based on evidence reviewed for the National Institute for health and care excellence safe staffing Guideline development. International Journal of Nursing Studies 2016;63:213-25.

7 McGillis Hall L, Doran D, Baker GR, et al. Nurse staffing models as predictors of patient outcomes. Medical Care 2003;41:1096-109.

8 Jelinek RC, Kavois JA. Nurse staffing and scheduling: past solutions and future directions. J Soc Health Syst 1992;3:75-82.

9 Burke EK, De Causmaecker P, van der Berghe G, et al. The state of the art of nurse Rostering. Journal of Scheduling 2004;7:441-99.

10 American Nurses Association. ANA's principles for nurse staffing 2012.

11 Kramer M, Schmalenberg C. Revising the essentials of magnetism tool. JONA: The Journal of Nursing Administration 2005;35:188-98.

12 Saville CE, Griffiths P, Ball JE, et al. How many nurses do we need? A review and discussion of operational research techniques applied to nurse staffing. International Journal of Nursing Studies 2019;97:7-13.

13 Griffiths P, Saville C, Ball J, et al. Nursing workload, Nurse Staffing Methodologies \& Tools: a systematic scoping review \& discussion. International Journal of Nursing Studies 2020;103.

14 Kortbeek N, Braaksma A, Burger CAJ, et al. Flexible nurse staffing based on hourly bed census predictions. International Journal of Production Economics 2015;161:167-80.

15 Twigg D, Duffield C. A review of workload measures: a context for a new staffing methodology in Western Australia. International Journal of Nursing Studies 2009;46:132-40.

16 Upenieks VV, Kotlerman J, Akhavan J, et al. Assessing nursing staffing ratios: variability in workload intensity. Policy, Politics, \& Nursing Practice 2007;8:7-19.

17 Alghamdi M. Nursing workload: a concept analysis. Journal of Nursing Management 2016;24:449-57.

18 Fasoli DR, Haddock KS. Results of an integrative review of patient classification systems. Annual Review of Nursing Research 2010;28:295-316.

19 McGillis Hall L, Pink L, Lalonde M, et al. Decision making for nurse staffing: Canadian perspectives. Policy, Politics, \& Nursing Practice 2006;7:261-9.

20 Fagerström L, Rainio A-K, Rauhala A, et al. Validation of a new method for patient classification, the Oulu patient classification. Journal of Advanced Nursing 2000;31:481-90.

21 van Oostveen CJ, Ubbink DT, Mens MA, et al. Pre-implementation studies of a workforce planning tool for nurse staffing and human resource management in university hospitals. Journal of Nursing Management 2016;24:184-91.

22 Rubio S, Díaz E, Martín J, et al. Evaluation of subjective mental workload: a comparison of SWAT, NASA-TLX, and workload profile methods. Applied Psychology 2004;53:61-86.

23 Hughes M. Nursing workload: an unquantifiable entity. Journal of Nursing Management 1999;7:317-22.

24 Choi J, Staggs VS. Comparability of nurse staffing measures in examining the relationship between $\mathrm{Rn}$ staffing and unit-acquired pressure ulcers: a unit-level descriptive, correlational study. International Journal of Nursing Studies 2014;51:1344-52.

25 McHugh MD, Stimpfel AW. Nurse reported quality of care: a measure of hospital quality. Research in Nursing \& Health 2012;35:566-75.

26 Leary A, Punshon G. Determining acute nurse staffing: a hermeneutic review of an evolving science. BMJ Open 2019;9:e025654.

27 Hyun S, Bakken S, Douglas K, et al. Evidence-Based staffing: potential roles for informatics. Nurse Econ 2008;26:151-73.

28 Tricco AC, Lillie E, Zarin W, et al. PRISMA extension for scoping reviews (PRISMA-ScR): checklist and explanation. Annals of Internal Medicine 2018;169:467.

29 National Institute for Clinical Excellence. Methods for the development of NICE public health guidance. 3. Londen: NICE, 2012. 
30 Mokkink LB, de Vet HCW, Prinsen CAC, et al. COSMIN risk of bias checklist for systematic reviews of patient-reported outcome measures. Quality of Life Research : An International Journal of Quality of Life Aspects of Treatment, Care and Rehabilitation - Official Journal of the International Society of Quality of Life Research 2018;27:1171-9.

31 Prinsen CAC, Mokkink LB, Bouter LM, et al. COSMIN guideline for systematic reviews of patient-reported outcome measures. Quality of Life Research : An International Journal of Quality of Life Aspects of Treatment, Care and Rehabilitation - Official Journal of the International Society of Quality of Life Research 2018;27:1147-57.

32 Donabedian A. Evaluating the quality of medical care. Milbank Quarterly 2005;83:691-729.

33 O'Brien-Pallas L, Meyer RM, Hayes LJ, et al. The Patient Care Delivery Model - an open system framework: conceptualisation, literature review and analytical strategy. Journal of Clinical Nursing 2011;20:1640-50.

34 Aiken LH, Patrician PA. Measuring organizational traits of hospitals: the revised nursing work index. Nursing Research 2000;49:146-53.

35 Ducharme MP, Bernhardt JM, Padula CA, et al. The professional practice environment, and nurse engagement in essential nursing practice. Journal of Nursing Administration 2017;47:367-75.

36 Gerolamo AM. An exploratory analysis of the relationship between psychiatric nurses' perceptions of workload and unit activity. Archives of Psychiatric Nursing 2009;23:243-50.

37 Kalisch BJ. Lee KHDU school or nursing, Durham, North Carolina, 27710. variations of nursing teamwork by Hospital, patient unit, and staff characteristics. Applied Nursing Research 2013;26:2-9.

38 Kalisch BJ, Williams RA. Development and psychometric testing of a tool to measure missed nursing care. JONA: The Journal of Nursing Administration 2009;39:211-9.

39 Kalisch BJ, Lee H, Rochman M. Nursing staff teamwork and job satisfaction. J Nurs Manage 2010;18:938-47.

40 Kalisch BJ, Tschannen D, Lee H, et al. Hospital variation in missed nursing care. Am J Med Qual 2011;26:291-9.

41 Lake ET. Development of the practice environment scale of the nursing work index $\ddagger$. Research in Nursing \& Health 2002;25:176-88.

42 Nelson-Brantley HV, Park SH, Bergquist-Beringer S. Characteristics of the nursing practice environment associated with lower UnitLevel Rn turnover. Journal of Nursing Administration 2018;48:31-7.

43 Trivedi V, Hancock W. Measurement of Nursing Work Load Using Head Nurses' Perceptions. Nursing Research 1975;24:371-6.

44 Williams MA, Murphy LN. Subjective and objective measures of staffing adequacy. JONA: The Journal of Nursing Administration 1979;9:21-9.

45 O'Brien-Pallas L, XM L, Wang S, et al. Evaluation of a patient care delivery model: system outcomes in acute cardiac care. CJNR 2010;42:98-120.

46 Pineau Stam LM, Spence Laschinger HK, Regan S, et al. The influence of personal and workplace resources on new graduate nurses' job satisfaction. Journal of Nursing Management 2015;23:190-9.

47 De Groot HA, Burke LJ, George VM. Implementing the differentiated pay structure model: process and outcomes. The Journal of Nursing Administration 1998;28:28-38.

48 Kalisch BJ, Lee H, Salas E. The development and testing of the nursing teamwork survey. Nursing Research 2010;59:42.

49 Bae S-H, Brewer CS, Kelly M, et al. Use of temporary nursing staff and nosocomial infections in intensive care units. Journal of Clinical Nursing 2015;24:980-90.

50 AACN healthy work environment assessment tool, 2015 Available: https://www.aacn.org/nursing-excellence/healthy-workenvironments/aacn-healthy-work-environment-assessment-too [Accessed December 11, 2019].

51 Choi J, Bakken S, Larson E, et al. Perceived nursing work environment of critical care nurses. Nursing Research 2004;53:370-8.

52 Kalisch B, Tschannen D, Lee H. Does missed nursing care predict job satisfaction? Journal of Healthcare Management / American College of Healthcare Executives 2011;56:117-31.

$53 \mathrm{Kim}$ S-S, Okechukwu CA, Dennerlein JT, et al. Association between perceived inadequate staffing and musculoskeletal pain among hospital patient care workers. International Archives of Occupational and Environmental Health 2014;87:323-30.

54 Reeder TJ, Burleson DL, Garrison HG. The overcrowded emergency department: a comparison of staff perceptions. Academic Emergency Medicine 2003;10:1059-64.

55 Sorra J, Nieva V. Hospital survey on patient safety culture 2004.
56 Spence Laschinger $\mathrm{H}$. Hospital nurses' perceptions of respect and organizational justice. JONA: The Journal of Nursing Administration 2004;34:354-64.

57 Rochon A, Heale R, Hunt E, et al. Teamwork and patient care teams in an acute care hospital. Nurs Leadersh 2015;28:28-39.

58 Mark B, Salyer J, Harless D. What explains nurses' perceptions of staffing adequacy? JONA: The Journal of Nursing Administration 2002;32:234-42.

59 Kalisch BJ, Friese CR, Choi SH, et al. Hospital nurse staffing: choice of measure matters. Medical Care 2011;49:775-9.

60 Bachnick S, Ausserhofer D, Baernholdt M, et al. Patient-Centered care, nurse work environment and implicit rationing of nursing care in Swiss acute care hospitals: a cross-sectional multi-center study. International Journal of Nursing Studies 2018;81:98-106.

61 Bonneterre V, Ehlinger V, Balducci F, et al. Validation of an instrument for measuring psychosocial and organisational work constraints detrimental to health among hospital workers: the NWI-EO questionnaire. International Journal of Nursing Studies 2011:48:557-67.

62 Bragadóttir H, Kalisch BJ, Tryggvadóttir GB. Correlates and predictors of missed nursing care in hospitals. Journal of Clinical Nursing 2017;26:1524-34.

63 Desmedt M, De Geest S, Schubert M, et al. Ausserhofer D. a multi-method study on the quality of the nurse work environment in acute-care hospitals: positioning Switzerland in the magnet Hospital research. Swiss Medical Weekly 2012;142:w13733.

64 Fagerström L, Rainio A-K. Professional assessment of optimal nursing care intensity level: a new method of assessing personnel resources for nursing care. Journal of Clinical Nursing 1999;8:369-79.

65 Fuentelsaz-Gallego C, Moreno-Casbas T, Gomez-Garcia T, et al. Work setting, satisfaction and burnout of the nurses in critical care units and hospitalization units. RN4CAST-Spain project. Enferm Intensiva 2013;24:104-12.

66 Gunnarsdóttir S, Clarke SP, Rafferty AM, et al. Staffing and nursedoctor relationships as predictors of nurse and patient outcomes. A survey of Icelandic Hospital nurses. International Journal of Nursing Studies 2009;46:920-7.

67 Jolivet A, Caroly S, Ehlinger V, et al. Linking hospital workers' organisational work environment to depressive symptoms: A mediating effect of effort-reward imbalance? The ORSOSA study. Social Science \& Medicine 2010;71:534-40.

68 Leineweber C, Westerlund H, Chungkham HS, et al. Nurses' practice environment and work-family conflict in relation to burn out: A multilevel modelling approach. PLoS ONE 2014;9:e96991.

69 Rauhala A, Fagerström L. Are nurses' assessments of their workload affected by non-patient factors? An analysis of the RAFAELA system. Journal of Nursing Management 2007;15:490-9.

70 Schubert M, Glass TR, Clarke SP, et al. Validation of the Basel extent of rationing of nursing care instrument. Nursing Research 2007:56:416-24.

71 Smeds Alenius L, Tishelman C, Runesdotter S, et al. Staffing and resource adequacy strongly related to RNs' assessment of patient safety: a national study of RNs working in acute-care hospitals in Sweden. BMJ Quality \& Safety 2014;23:242-9.

72 Stalpers D, Van Der Linden D, Kaljouw MJ, et al. Nurse-perceived quality of care in intensive care units and associations with work environment characteristics: a multicentre survey study. J Adv Nurs 2017;73:1482-90.

73 Tvedt C, Sjetne IS, Helgeland J, et al. An observational study: associations between nurse-reported Hospital characteristics and estimated 30-day survival probabilities. BMJ Qual Saf 2014;23:757-64.

74 Tvedt C, Sjetne IS, Helgeland J, et al. Nurses' reports of staffing adequacy and surgical site infections: A cross-sectional multicentre study. Int J Nurs Stud 2017;75:58-64.

75 Zander B, Dobler L, Busse R. The introduction of DRG funding and hospital nurses' changing perceptions of their practice environment, quality of care and satisfaction: Comparison of cross-sectional surveys over a 10-year period. International Journal of Nursing Studies 2013;50:219-29.

76 Heinen MM, van Achterberg T, Schwendimann R, et al. Nurses' intention to leave their profession: A cross sectional observational study in 10 European countries. International Journal of Nursing Studies 2013;50:174-84

77 Louch G, O'Hara J, Gardner P, et al. The daily relationships between staffing, safety perceptions and personality in hospital nursing: a longitudinal on-line diary study. International Journal of Nursing Studies 2016;59:27-37. 
78 Bruyneel L, Heede KV, Diya L, et al. Predictive validity of the International Hospital outcomes study questionnaire: an RN4CAST pilot study. Journal of Nursing Scholarship 2009;41:202-10.

79 Bragadóttir H, Kalisch BJ, Bergthóra Tryggvadóttir G. The extent to which adequacy of staffing predicts nursing teamwork in hospitals. Journal of Clinical Nursing 2019;28:4298-309.

80 Sasso L, Bagnasco A, Catania G, et al. Push and pull factors of nurses' intention to leave. Journal of Nursing Management 2019;27:946-54.

81 Sharma N, Herrnschmidt J, Claes V, et al. Organizational readiness for implementing change in acute care hospitals: an analysis of a cross-sectional, multicentre study. Journal of Advanced Nursing 2018;74:2798-808.

82 Weigl M, Schmuck F, Heiden B, et al. Associations of understaffing and cardiovascular health of hospital care providers: a multi-source study. International Journal of Nursing Studies 2019;99.

83 Asiret GD. Attitudes and satisfaction of nurses with the work environment in turkey. International Journal of Caring Sciences 2017;10:771-80.

84 Escobar-Aguilar G, Gómez-García T, Ignacio-García E, et al. Work environment and patient safety: data comparison between Seneca and RN4CAST projects. Enfermeria Clinica 2013;23:103-13.

85 Anzai E, Douglas C, Bonner A. Nursing practice environment, quality of care, and morale of hospital nurses in Japan. Nurs Health Sci 2014;16:171-8.

86 Cho S, June KJ, Kim YM, et al. Nurse staffing, quality of nursing care and nurse job outcomes in intensive care units. Journal of Clinical Nursing 2009;18:1729-37.

87 Cho S, Mark BA, Knafl G, et al. Relationships Between Nurse Staffing and Patients' Experiences, and the Mediating Effects of Missed Nursing Care. Journal of Nursing Scholarship 2017;49:347-55.

88 Jafree SR, Zakar R. Nurse perceptions of organizational culture and its association with the culture of error reporting: a case of public sector hospitals in Pakistan. BMC Health Services Research 2016:16:1-13.

89 Lin S-Y, Chiang H-Y, Chen I-L. Comparing nurses' intent to leave or stay: Differences of practice environment perceptions. Nursing \& Health Sciences 2011;13:463-7.

90 Spence K, Tarnow-Mordi W, Duncan G, et al. Measuring nursing workload in neonatal intensive care. Journal of Nursing Management 2006;14:227-34.

91 Hegney DG, Rees CS, Osseiran-Moisson R, et al. Perceptions of nursing workloads and contributing factors, and their impact on implicit care rationing: a Queensland, Australia study. Journal of Nursing Management 2019;27:371-80.

92 Roche M, Duffield C. A comparison of the nursing practice environment in mental health and medical-surgical settings. Journal of Nursing Scholarship 2010;42:195-206.

93 Roche M, Duffield C, White E. Factors in the practice environment of nurses working in inpatient mental health: a partial least squares path modeling approach. International Journal of Nursing Studies 2011;48:1475-86.

94 Burmeister EA, Kalisch BJ, Xie B, et al. Determinants of nurse absenteeism and intent to leave: an international study. Journal of Nursing Management 2019;27:143-53.

95 Shin S, Park JH, Bae SH. Nurse staffing and nurse outcomes: a systematic review and meta-analysis. Nursing Outlook 2018;66:273-82.

96 van Oostveen CJ, Mathijssen E, Vermeulen H. Nurse staffing issues are just the tip of the iceberg: A qualitative study about nurses' perceptions of nurse staffing. International Journal of Nursing Studies 2015;52:1300-9.

97 Fagerström L, Kinnunen M, Saarela J. Nursing workload, patient safety incidents and mortality: an observational study from Finland. BMJ Open 2018;8:e016367.

98 Kramer M, Schmalenberg C. Development and evaluation of essentials of magnetism tool. The Journal of Nursing Administration 2004;34:365-78.

99 van den Oetelaar W, van Stel $\mathrm{H}$, van Rhenen W, et al. Balancing nurses' workload in hospital wards: study protocol of developing a method to manage workload. BMJ Open 2016;6:1-11.

100 van Oostveen CJ, Vermeulen H, Gouma DJ, et al. Explaining the amount of care needed by hospitalised surgical patients: a prospective time and motion study. BMC Health Services Research 2013;13.

101 Fasoli DR, Fincke BG, Haddock KS. Going beyond patient classification systems to create an evidence-based staffing methodology. The Journal of Nursing Administration 2011;41:434-9.

102 Myny D, Van Goubergen D, Gobert M, et al. Non-direct patient care factors influencing nursing workload: a review of the literature. $J$ Adv Nurs 2011;67:2109-29.

103 Goossen WTF, Epping P, Van den Heuvel WJAet al. Development of the nursing minimum data set for the Netherlands (NMDSN): identification of categories and items. J Adv Nurs 2000;31:536-47.

104 Trivedi VM, Warner DM. A branch and bound algorithm for optimum allocation of float nurses. Manage Sci 1976;22:972-81.

105 de Vet HCW, Terwee CB, Mokkink LB, et al. Measurement in medicine : a practical guide. Cambridge: Cambridge University Press, 2011.

106 Sloan J, Aaronson N, Cappelleri J, et al. Assessing the clinical significance of single items relative to summated scores. Clin Ther 2002;24:6-7.

107 Schmalenberg C, Kramer M. Perception of adequacy of staffing Crit Care Nurse 2009;29:65-71.

108 Aiken LH, Sloane DM, Bruyneel L, et al. Nurse staffing and education and hospital mortality in nine European countries: a retrospective observational study. Lancet 2014;383:1824-30.

109 Munn Z, Peters MDJ, Stern C, et al. Systematic review or scoping review? guidance for authors when choosing between a systematic or scoping review approach. BMC Med Res Methodol 2018;18.

110 Unruh L. Nurse staffing and patient, nurse, and financial outcomes. Am J Nurs 2008;108:62-71. 